\title{
Effect of Maturation on Heart Rate Response to Ocular Compression Test during Rapid Eye Movement Sleep in Human Infants ${ }^{1}$
}

\author{
J. RAMET, ${ }^{2}$ J. P. PRAUD, A. M. D'AlleSt, A. CAROFILIS, M. DEHAN, C. GUILLEMINAULT ${ }^{3}$ \\ AND Cl. GAULTIER \\ Laboratory of Physiology and Neonatal Unit [A.C., M.D.], CNRS UA 1159, Hospital A. Béclère, \\ 92141 Clamart, France
}

\begin{abstract}
Thirty-three premature and full-term infants (31.5-50 wk postconceptional age) free from neurologic and cardiopulmonary disease at time of testing, underwent a standardized ocular compression test during polygraphically controlled rapid eye movement sleep. $R R$ intervals were measured on the ECG before and during ocular compression. RR interval changes during ocular compression were compared to the preceding 60-s mean RR interval in each infant. Results were analyzed relative to gestational age, postnatal age, and postconceptional age. Baseline heart rate during REM sleep decreased with postconceptional age. During ocular compression, there was a significant negative correlation between the longest $R R$ interval or the "latency" variable with postconceptional age. Latency is defined as the time, in milliseconds, from beginning of eyelid pressure to the first measurable $R R$ increase compared to mean control RR + 1 SD. Our results indicate that during rapid eye movement sleep, "baseline heart rate" decreases with maturation, an effect supposedly related to increased vagal activity, whereas the heart rate response on ocular pressure stimulus, a vagally mediated reflex, is significantly influenced and blunted with maturation. (Pediatr Res 24: 477-480, 1988)
\end{abstract}

\section{Abbreviations}

REM, rapid eye movement

NREM, non-REM

GA, gestational age

PNA, postnatal age

PCA, postconceptional age

MEMA, middle ear muscle activity

Long isolated sinus pauses have been reported during systematic Holter ECG of early premature infants (1). Our knowledge of the autonomic system balance and autonomic regulation of heart rate in premature infants is incomplete. It is assumed that a prominence of vagal tone exists in premature infants $(2,3)$. The understanding of factors controlling heart rate is rendered more complex by the known impact of the different states of

Received February 29, 1988; accepted June 14, 1988.

Correspondence Cl. Gaultier, Laboratory of Physiology, Hospital Antoine Béclère, 92141 -Clamart, France.

Supported by Grants from the Faculty of Medicine Paris XI, CNRS, and the AZ.VUB of Brussels, Belgium.

${ }^{1}$ Presented in part at the Annual meeting of the American Thoracic Society, New Orleans, LA, 1987.

${ }^{2}$ Present address Department of Pediatrics, Vrije Universiteit, 1090 Brussels, Belgium.

${ }^{3}$ Present address Sleep Disorders Center, Stanford University, Stanford, CT. alertness (wake, REM, and NREM sleep) on the autonomic nervous control system balance in human infants $(4,5)$. Observations obtained during waking hours cannot be extrapolated to explain sleep-related changes. Also it is hazardous to extrapolate from data obtained in young mammals to human infants as sleep-state maturation may be species related (6-8). Finally one must remember that full-term human newborns spend up to $70 \%$ of their total sleep time in "active" or REM sleep, and that REM sleep is even more prominent during the 24-h period in premature infants (9). To appreciate the effect of maturation on a well-known reflex involving the autonomic nervous system, we performed controlled ocular compression during polygraphically documented REM sleep to evaluate the heart rate response as a function of maturation in premature infants.

\section{MATERIALS AND METHODS}

Seventeen premature and 16 full-term infants ( 20 boys and 13 girls) were studied. All were free of neurologic and cardiopulmonary disease at the time of testing. Parental informed consent was obtained in each instance. GA ranged from 26.5 to $40 \mathrm{wk}$, PNA from 5 to 76 days, and PCA from 31.5 to $50 \mathrm{wk}$ (see Table 1).

An ocular compression test was performed in a standardized manner, between 0900 and $1300 \mathrm{~h}$, and at least $1 \mathrm{~h}$ after feeding. Infants were asleep on their backs. All were in active (REM) sleep just before and during the testing period as documented by polygraphic monitoring of ECG, respiration, and electroencephalogram potentials (EEG, $\mathrm{F}_{\mathrm{p} 2}-\mathrm{C}_{4}$, and $\mathrm{C}_{4}-\mathrm{T}_{4}$ of the $10-20$ international placement system), and by continuous behavioral observation. The ECG was recorded using bipolar chest leads (DI lead). Biologic variables were monitored on an ALVAR 16 channels polygraph at $15 \mathrm{~mm} / \mathrm{s}$ speed.

To perform the ocular compression, a water-filled pressure sensor (external diameter: $18 \mathrm{~mm}$ ) was gently placed on each infant's eyelid just before testing. Each pressure sensor was connected to a pressure transducer (Hewlett-Packard Co., Palo Alto, CA) and the applied pressure to each sensor was recorded on the ALVAR polygraph simultaneously with the other variables (see Fig. 1). The mean and SD manually applied pressure recorded via the water-filled sensors was $103 \pm 9 \mathrm{~mm} \mathrm{Hg}$. The pressure applied to each sensor was identical for each eye as documented by the polygraphic trace and was maintained without change during $10 \mathrm{~s}$; a square wave stimulation was, thus, performed with an identical pressure applied on both eyes during a constant stimulation period (10 s) (see Fig. 1).

Polygraphic analysis and behavioral scoring were performed to affirm absence of state of alertness change during the minutes before, during, and just after testing. RR intervals were measured on the ECG recording during the minutes before and during ocular compression and after variables were collected. 
RAMET $E T A L$.

Table 1. Subjects, age, and ocular compression test results*

\begin{tabular}{|c|c|c|c|c|c|c|c|c|}
\hline \multirow[b]{2}{*}{ Subject } & \multirow[b]{2}{*}{$\begin{array}{l}\text { GA } \\
\text { (wk) }\end{array}$} & \multirow[b]{2}{*}{$\begin{array}{l}\text { PNA } \\
\text { (day) }\end{array}$} & \multirow[b]{2}{*}{$\begin{array}{l}\text { PCA } \\
\text { (wk) }\end{array}$} & \multicolumn{2}{|c|}{ Control RR } & \multirow[b]{2}{*}{$\begin{array}{l}\text { Latency } \\
(\mathrm{ms})\end{array}$} & \multirow{2}{*}{$\begin{array}{l}\text { Longest RR } \\
\text { interval } \\
\text { (ms) }\end{array}$} & \multirow[b]{2}{*}{$\begin{array}{c}\% \mathrm{RR} \\
\text { maximum }\end{array}$} \\
\hline & & & & $\begin{array}{c}\text { Mean } \\
\text { (ms) }\end{array}$ & $\begin{array}{l}\mathrm{SD} \\
(\mathrm{ms})\end{array}$ & & & \\
\hline 1 & 30.5 & 6 & 31.5 & 398 & 18 & 2400 & 1733 & 435 \\
\hline 2 & 31.0 & 8 & 32.0 & 440 & 21 & 440 & 1867 & 424 \\
\hline 3 & 31.5 & 5 & 32.0 & 437 & 11 & 500 & 1800 & 412 \\
\hline 4 & 26.5 & 46 & 33.0 & 399 & 17 & 433 & 1033 & 259 \\
\hline 5 & 31.5 & 11 & 33.0 & 441 & 24 & 1800 & 1666 & 378 \\
\hline 6 & 32.0 & 19 & 34.5 & 436 & 21 & 600 & 1866 & 428 \\
\hline 7 & 34.0 & 7 & 35.0 & 446 & 25 & 2630 & 1233 & 276 \\
\hline 8 & 35.0 & 10 & 36.5 & 392 & 17 & 1233 & 933 & 238 \\
\hline 9 & 35.0 & 15 & 37.0 & 440 & 22 & 1833 & 1066 & 242 \\
\hline 10 & 32.0 & 36 & 37.0 & 442 & 21 & 1633 & 1071 & 242 \\
\hline 11 & 36.5 & 6 & 37.5 & 434 & 25 & 2000 & 666 & 153 \\
\hline 12 & 30.0 & 52 & 37.5 & 406 & 24 & 1600 & 869 & 214 \\
\hline 13 & 35.5 & 17 & 38.0 & 441 & 14 & 890 & 845 & 192 \\
\hline 14 & 37.0 & 10 & 38.5 & 434 & 19 & 2160 & 1200 & 277 \\
\hline 15 & 35.5 & 20 & 38.5 & 412 & 23 & 1200 & 833 & 202 \\
\hline 16 & 29.5 & 70 & 39.5 & 435 & 7 & 2050 & 733 & 169 \\
\hline 17 & 29.0 & 73 & 39.5 & 396 & 11 & 3350 & 666 & 168 \\
\hline 18 & 38.5 & 18 & 41.0 & 430 & 18 & 2400 & 566 & 132 \\
\hline 19 & 40.0 & 10 & 41.5 & 434 & 18 & 600 & 833 & 192 \\
\hline 20 & 39.5 & 25 & 43.5 & 430 & 9 & 2800 & 1000 & 233 \\
\hline 21 & 39.5 & 26 & 43.5 & 431 & 7 & 4000 & 700 & 162 \\
\hline 22 & 40.0 & 28 & 44.0 & 430 & 10 & 3200 & 600 & 140 \\
\hline 23 & 39.5 & 31 & 44.0 & 408 & 15 & 3150 & 700 & 172 \\
\hline 24 & 40.0 & 35 & 45.0 & 398 & 7 & 1900 & 800 & 201 \\
\hline $25^{*}$ & 39.5 & 36 & 45.0 & 469 & 10 & & & \\
\hline $26^{*}$ & 40.5 & 39 & 45.5 & 430 & 9 & & & \\
\hline 27 & 40.0 & 41 & 46.0 & 401 & 6 & 2600 & 666 & 166 \\
\hline 28 & 39.5 & 44 & 46.0 & 498 & 7 & 2850 & 600 & 120 \\
\hline 29 & 40.0 & 50 & 47.0 & 509 & 4 & 2200 & 533 & 105 \\
\hline 30 & 40.0 & 56 & 48.0 & 469 & 9 & 5200 & 533 & 114 \\
\hline 31 & 39.5 & 58 & 48.0 & 464 & 7 & 2900 & 666 & 144 \\
\hline 32 & 38.5 & 73 & 49.0 & 471 & 12 & 4050 & 666 & 141 \\
\hline 33 & 39.0 & 76 & 50.0 & 431 & 7 & 3700 & 533 & 124 \\
\hline
\end{tabular}

* Control RR interval is the mean RR interval determined from measurement of each RR interval recorded during the $60 \mathrm{~s}$ just preceding the ocular compression test, RR interval is expressed in milliseconds ( $\pm 1 \mathrm{SD}$ ); "latency" is latency from applied eyelid pressure to the first measurable $R R$ interval-increase compared to mean control $R R+1 \mathrm{SD}$ expressed in $\mathrm{ms}$; longest $\mathrm{RR}$ interval is the duration of the longest $\mathrm{RR}$ interval in $\mathrm{ms}$ noted just after eyelid pressure; \% RR maximum is the longest RR interval in ms just after eye-lid pressure divided by mean control RR, in ms, multiplied by 100 . Subjects 25 and 26 had no response to ocular compression test, RR interval during ocular compression test was similar to control RR interval and \% RR maximum was $100 \%$.
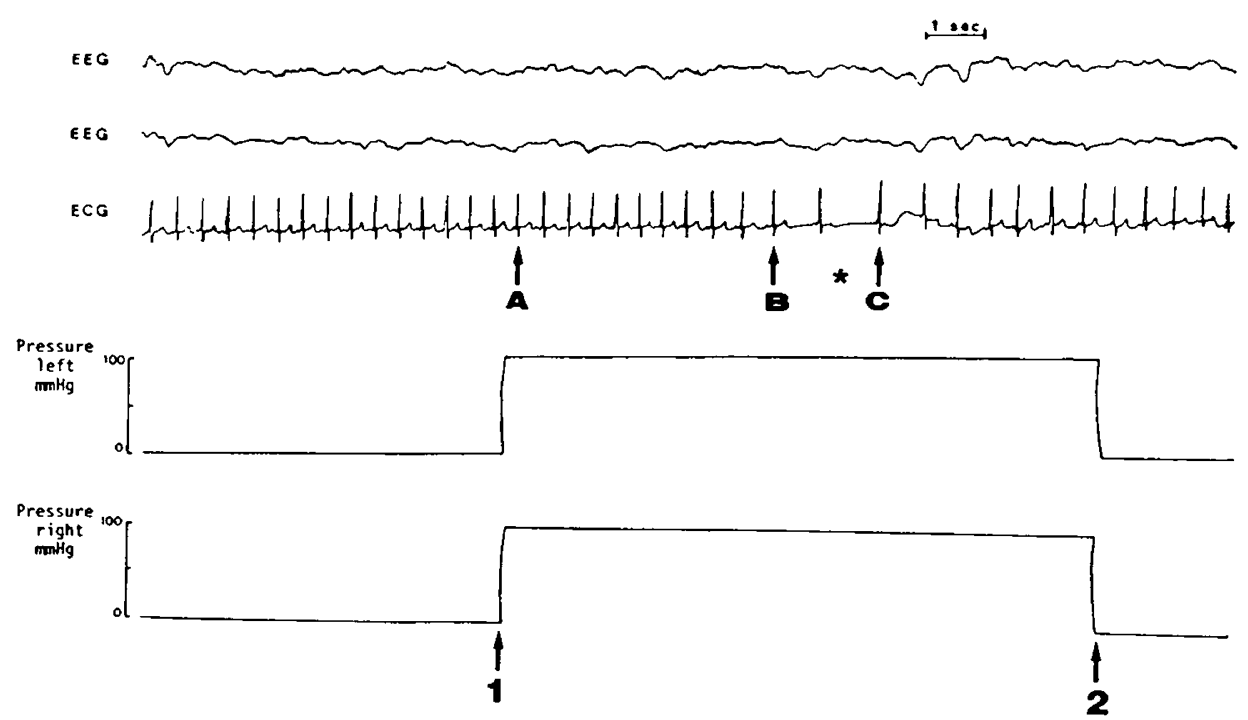

Fig. 1. Channel 1: EEG $\mathrm{F}_{\mathrm{p} 2}-\mathrm{C}_{4}$; channel 2: $\mathrm{EEG} \mathrm{C}_{4}-\mathrm{T}_{4}$; channel 3: ECG DI. 1 . Control RR is defined by calculating the mean heart rate during $60 \mathrm{~s}$ terminating at onset of stimulation (i.e. point $A$ ). 2. Heart rate between points $A$ and $B$ is defined as latency. $3 .{ }^{*}$ indicates longest RR. Channel 4 and 5: measurement of left and right eyelid pressure; pressure is applied in arrow 1 and withdrawn in arrow 2. The pressure lasted for $10 \mathrm{~s}$. Note the maintainance of REM sleep EEG throughout the recording. No arousal is noted with pressure onset and offset (arrows 1 and 2). 
The intervals were: 1 ) the control RR interval defined as the mean RR interval determined from measurement of each $R R$ interval recorded during the $60 \mathrm{~s}$ before the ocular compression; 2) the longest RR interval, in milliseconds noted just after eyelid pressure, the percent RR maximum was defined as the longest $\mathrm{RR}$ interval in milliseconds just after eyelid pressure divided by mean control RR, in milliseconds, multiplied by 100 , i.e. \% RR maximum; 3) the latency from applied eyelid pressure to the first measurable RR interval increase compared to mean control $R R+1 S D$, expressed in milliseconds.

A Pearson coefficient correlation analysis was performed to establish independence of specific variables. Correlations between age (postconceptional age) and measured variables were performed using linear and/or multiplicative regression. Multiple and stepwise linear regression analyses were performed with gestational and postnatal ages selected as independent variables. The "dbase III" statistical package was used to perform statistical computation.

\section{RESULTS}

All variables were measured during uninterrupted REM (active) sleep, but no dissociation between "phasic" and "tonic" REM sleep was attempted (see Fig. 1 which illustrates a typical tracing). Any record where a sleep state change occurred or where the persistance of the REM sleep state was questioned during application of ocular pressure, was eliminated from the analysis. Less than $5 \%$ of the total number of challenge tests were discarded. Data obtained in each infant are summarized in Table 1. Two of the full-term infants had no response (nos. 25 and 26) to our mild stimulus and most full-term infants had only a mild to moderate $R R$ interval lengthening in response to the ocular pressure at the preselected setting.

There was a clear effect of maturation on mean control RR, on the longest RR interval secondary to ocular compression, and on the latency variables. When multiplicative analyses were performed for these variables relative to postconceptional age, mean control RR, longest RR interval, and latency were significantly influenced by postconceptional age (see Table 2). Not too surprisingly "\% RR maximum" which had a high correlation coefficient with longest RR interval, was also statistically influenced by postconceptional age (Table 2; and Fig. 2).

Stepwise linear regression analyses performed after determination of the statistical independence of the selected variables confirmed the effect of maturation on the ocular compression variables (Table 3 ). With longest $R R$ interval or \% RR maximum as dependent variables and GA and PNA as independent variables, the stepwise regression for longest $R R$ interval gave a $R^{2}$ for the full regression of $0.64(p<0.0001, \mathrm{~F}=18.46)$ (longest $\mathrm{RR}$ interval $=2398-61.4 \mathrm{GA}+10.1 \mathrm{PNA}+2.5$ control RR). A similar analysis performed with \% RR maximum indicated a $\mathrm{R}^{2}$ for the full regression of $0.69(p<0.0001, \mathrm{~F}=31.4)(\% \mathrm{RR}$ maximum $=790-13.8 \mathrm{GA}+2.4 \mathrm{PNA})$. With latency as the dependent variable, the $\mathrm{R}^{2}$ for the full regression was $0.51(p<$ $0.0002, F=9.41$ ) (latency $=-3197+138 \mathrm{GA}+25.9$ PNA) (Table 3).

\section{COMMENTS}

In 1908, Aschner (10) and Dagnini (11) published early descriptions of the oculocardiac reflex and reported cardiac rhythm

Table 2. Results of multiplicative analyses*

\begin{tabular}{lrl}
\hline $\begin{array}{c}\text { Effect of maturation } \\
\text { (PCA) on: }\end{array}$ & F & \multicolumn{1}{c}{$p$} \\
\hline Control RR & 5.75 & $<0.03$ \\
Longest RR interval & 78.14 & $<0.0001$ \\
\%RR maximum & 94.68 & $<0.0001$ \\
Latency & 25.05 & $<0.0001$ \\
\hline
\end{tabular}

* Variables were significantly influenced by PCA.

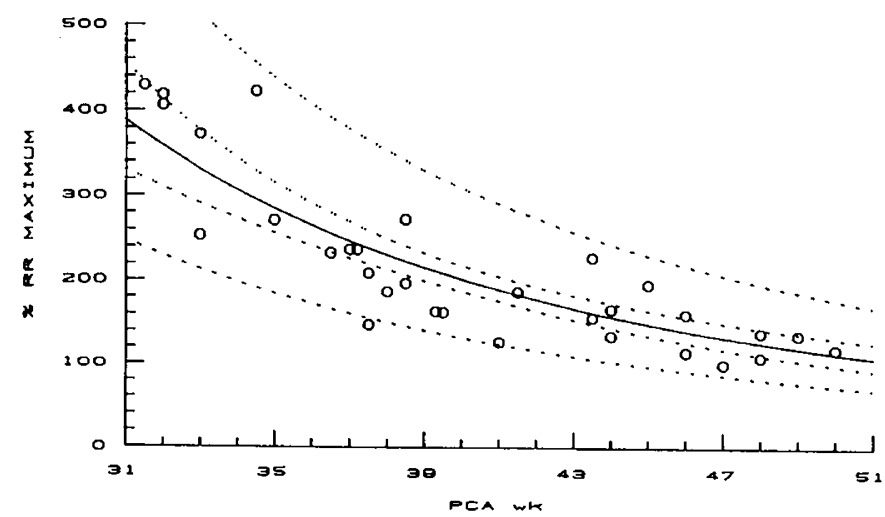

Fig. 2. Abscissa: PCA in weeks; ordinate: \% RR maximum, i.e. longest $R R$ interval in ms divided by mean control $R R$ in ms multiplied by 100 . Longest $R R$ interval values were obtained after onset of eyelid pressure, during polygraphically controlled REM sleep (see text). There is a significant $\% \mathrm{RR}$ maximum decrease $(p<0.0001)$ with increasing $\mathrm{PCA}\left(\% \mathrm{RR}\right.$ maximum $\left.=2.75^{10} \mathrm{PCA}^{-2.58}\right)$.

Table 3. Results of stepwise regression for general measured variables*

\begin{tabular}{llccc}
\hline $\begin{array}{c}\text { Independent } \\
\text { variables }\end{array}$ & $\begin{array}{c}\text { Dependent } \\
\text { variables }\end{array}$ & $\begin{array}{c}\text { Partial } \\
\text { coefficients }\end{array}$ & $\begin{array}{c}\text { Partial } \\
\mathrm{R}^{2}\end{array}$ & $p$ \\
\hline Longest RR & GA & 55.3 & 0.35 & $<0.0001$ \\
& PNA & 10.2 & 0.30 & $<0.0001$ \\
\%RR maximum & GA & 114 & 0.38 & $<0.001$ \\
& PNA & 2.4 & 0.31 & $<0.001$ \\
Latency & GA & 136 & 0.28 & $<0.002$ \\
& PNA & 25.8 & 0.23 & $<0.001$ \\
\hline
\end{tabular}

* Variables were significantly influenced by PNA and GA.

slowing secondary to eyeball pressure on humans and experimental animals. This reflex involves an afferent pathway through the ophthalmic branch of the trigeminal nerve and an efferent pathway involving the motor nucleus of the vagus nerve and its cardiac efferents. Several authors (12-15) proposed assessing cardiac reactivity to vagal stimuli by evaluation of the amplitude of the cardiac response to ocular pressure, and Philips et al. (16) showed that such pressure evoked severe cardiac slowing in premature infants.

In our study we assessed the effect of maturation on response to ocular pressure in well-controlled conditions. Premature infants spend most of their time in REM sleep, and we paid great attention to define the state of alertness of infants during the entire testing procedure. We avoided heart rate changes related to crying, feeding, fear, and probably other emotional stresses associated with wake behavior (17-19). We could not dissociate tonic from phasic REM sleep. Even with the monitoring of MEMA, the best human indication of phasic events of REM sleep, this dissociation is never certain, as ponto-geniculo-occipital waves cannot be monitored in humans.

Our investigation clearly demonstrates a relationship between significant cardiac slowing and postconceptional age after vagal stimulation by ocular pressure. As a general rule the more premature the infant, the shorter was the latency from beginning of the pressure stimulus to the first prolonged RR interval, and the more important was the amplitude of the cardiac response assessed by the longest RR interval and \% RR maximum. However, full-term infants had a very limited response, and the response was completely lacking in two infants. This limited response can be related to the mildness of the stimulation (eyelid pressure $=103 \pm 9 \mathrm{~mm} \mathrm{Hg}$ ) (15), but this is not a sufficient explanation considering the amplitude of the response in more premature infants. A better parasympathetic-sympathetic interaction can be evoked as an associated factor. Probably it is too 
simple to attribute the blunting of the oculo-cardiac reflex to maturation of sympathetic activity. A more complex modulation of each arm of the autonomic nervous system by the other must occur with maturation. As several synapses can be identified on this arc reflex, one can imagine that maturation may lead to more complex controls at each synaptic relay.

Ocular compression allowed us to demonstrate the maturation of a certain autonomic balance when premature infants were submitted to specific challenges, and this autonomic balance implies enhanced sympathetic activity or decrease in vagal reactivity. The simultaneous slowing of baseline heart rate (i.e. "control RR interval") with postconceptional age during REM sleep must also be emphasized. This decrease is well known in infants (4) and kittens (7). Egbert and Katona (7) have shown in the kitten that, even if heart rate is higher during REM sleep than during quiet (NREM) sleep, there is development of a parasympathetic dominance with age during normal, unchallenged sleep. A possible effect of the maturation of the cardiac pacemaker itself cannot be well addressed from our study as it was cross-sectional and has rarely, if ever, been resolved in animal models (20). However, studies of pharmacologically denervated hearts in kittens or other mammals have shown that the intrinsic rate changes are species dependent and can be associated with an heart rate increase $(7,21-23)$. Even if this pacemaker maturation exists in humans, and plays a role in the baseline heart rate slowing as well as the decreased responsiveness to ocular pressure, it is usually accepted that a part of the heart rate reduction seen with sleep is linked to increased vagal control (5).

Finally, the stepwise regression analyses show that the ocular stimulus variables influenced by maturation (longest $R R$ interval and \% RR maximum or the latency) are dependent on both gestational and postnatal ages (which are included under the label "postconceptional age"). This finding that developmental changes in cardiac rate controls are functions both of gestational and postnatal ages is similar to what has been noted in investigations of cardiac control in full-term and preterm infants during sleep (5).

Acknowledgments. The authors thank C. Lebretonnic and A. Virassamy for their helpful technical assistance and S. Rouchaville for typing the manuscript.

\section{REFERENCES}

1. Valimäki IA, Rautaharjy PM, Roy SB, Scott KE 1974 Heart rate patterns in healthy term and preterm infants and in respiratory distress syndrome. Eur
J Cardiol 1:411-419

2. Hirsch EG 1970 Embryological and fetal development of cardiac innervation in the human heart. In: The Innervation of the Vertebrate Heart. Charles $C$ Thomas, Springfield, IL, 125-133

3. Gauthier P, Nadeau RA, De Champlain J 1975 The development of sympathetic innervation and the functional state of the cardiovascular system in newborn dogs. Can J Physiol Pharmacol 53:763-776

4. Harper RM, Hoppenbrouwers T, Sterman MB, McGinty DJ, Hodgman J 1976 Polygraphic studies of normal infants during the first six months of life. 1. Heart rate and variability as a function of state. Pediatr Res 10:945-948

5. Katona PG, Frasz A, Egbert J 1980 Maturation of cardiac control in fullterm and preterm infants during sleep. Early Hum Dev 4:145-159

6. Woods JR, Dandavino A, Murayama K, Brinkman CR, Assali N 1977 Autonomic control of cardiovascular functions during neonatal development and in adult sheep. Cir Res 40:401-407

7. Egbert JR, Katona PG 1980 Development of autonomic heart rate control in the kitten during sleep. Am J Physiol 238:H829-H835

8. Geis WP, Tatooles CJ, Priola DV, Friedman WF 1975 Factors influencing neurohumoral control of the heart in the newborn dog. Am J Physiol 228:1685-1689

9. Anders TF, Emde R, Parmelee A 1971 A Manual of Standardized Terminology, Techniques and Criteria for Scoring of States of Sleep and Wakefulness in Newborn Infants. UCLA Brain Information Service/BRI Publications Office, Los Angeles

10. Aschner B 1908 Uber einen bisher noch nicht beschreibenen Reflex Von Auge auf Kreislauf und Atmung: Verschwinden des Radialispulses bei Druk auf das Auge. Wien Klin Wochenschr 21:1529-1530

11. Dagnini G 1908 Intorno ad un reflesso provocato in alcuni emiplegici collo stimolo della cornea e colla pressione sul bulbo oculare. Bull Sci Med 8:380381

12. Gandevia SC, Mc Closkey DI, Potter EK 1978 Reflex bradycardia occurring in response to diving, nasopharyngeal stimulation and ocular pressure, and its modification by respiration and swallowing. J Physiol 276:383-394

13. Stephenson JBP 1980 Reflex anoxic seizures and ocular compression. Dev Med Child Neurol 22:380-386

14. Kahn A, Riazi J, Blum D 1983 Oculocardiac reflex in near miss for sudden infant death syndrome infants. Pediatrics 71:49-52

15. Blanc VR, Hardy JF, Milot J, Jacob JL 1983 The oculocardiac reflex: a graphic and statistical analysis in infants and children. Can Anaesth Soc $J$ 30:360369

16. Phillips SJ, Agate FJ Jr, Silverman WA, Steiner P 1964 Autonomic cardiac reactivity in premature infants. Biol Neonate 6:225-249

17. Lipton EL, Steinschneider A, Richmond JB 1965 Autonomic function in the neonate. VIII. Cardio-pulmonary observations. N Engl J Med 33:147-153

18. Vallbona C, Desmond MM, Rudolph AJ 1963 Cardiodynamic studies in the newborn. II. Regulation of the heart rate. Biol Neonate 5:159-199

19. Kaada B 1986 Sudden Infant Death Syndrome. The Possible Role of the Fear Paralysis Reflex. Norwegian University Press, Oslo

20. Vlk J, Vincenzi FF 1977 Functional autonomic innervation of mammalian cardiac pacemaker during the perinatal period. Biol Neonate 31:19-26

21. Vapaavouri EK, Shinebourne EA, Williams RL, Heyman MA, Rudolph AM 1977 Development of cardiovascular response in intact fetal and neonatal lambs. Biol Neonate 22:177-188

22. Levy MN, Zieske H 1969 Autonomic control of cardiac pacemaker activity and atrio-ventricular transmission. J Appl Physiol 27:465-470

23. Friedman WF 1972 The intrinsic physiological properties of the developing heart. Prog Cardiovasc Dis 15:87-111 